\title{
Strategy to Increase Waste Handling Quantity and Quality Services and Waste Recovery, and to Decrease Uncontrolled Waste Flow into Environment (Indonesia cases)
}

\author{
Enri Damanhuri - ITB \\ Mobile phone: $+62-8122330684$ \\ enri.damanhuri@gmail.com
}

\section{BACKGROUND AND FACTS}

- Waste amounts increased rapidly with economic growth. Not all of the waste generated are collected by municipalities due to their 'limited' capacity. Most of the formal waste collection are initiated, managed and operated by community (role of RTs/RWs).

- Almost of the cities rely on landfilling technology to dispose their waste collected. Land for new waste disposal sites for MSW is becoming difficult. Most of the landfilling process is open dumping.

- The central government (particularly Min PUPR and MIN KLHK) has tried to develop legal systems and policies for waste reduction and appropriate waste handling, and management measures as well for its implementation in local cities.

- The central government (Min KLHK) has also prepared a national policy, including national target for waste reduction, and waste handling services (year 2020 will be $100 \%$ waste services)

- Waste recovery program (known as 3 Rs program) is highly supported by government. The development of bank of garbage and TPS-3R/TPST are the common program that are implemented in Indonesia. The central government (particularly Min PUPR) has also assisted the local government for development of physical infrastructure and technical assistance as well, e.g. new sanitary landfill facilities, TPS-3R, TPST for waste handling. But in reality, not more than $10 \%$ (by weight NOT by volume!) of total waste generated has been recovered, and composted.

- The quality of waste recovery and its valorization effort are depend on the quality of waste separation. Waste separation activities at a community level has not yet been widely implemented.

- The dominant views in understanding the $3 R$ s concept are always associated with any effort in urban waste management. Only in rare cases these efforts are associated with sectors of industries and the roles of other informal sectors (other than scavengers). Recycling activity is supported because it is associated with the image of a green city. But very rarely the waste recovery in MSW management associated with efforts to gain quality of recyclable waste in accordance with the quality required by recycling market. 


\section{STRATEGY}

- Improvement of waste management is a key focus of the strategy.

- Some cities may have set a goal of reducing the amount of waste recovery and waste disposed off at the final disposal site in a target year

- To achieve this, the city needs to measure based on an action plan that includes both community-based activities and the city government's efforts to increase waste collection, and to introduce waste separation at home and operation of an intermediate treatment facility for waste reduction.

- The focus of the strategy should be:

1. How to increase the waste collection rate and services and to improve its quality

2. How to increase the waste recovery and to improve the quality of recyclable materials

3. How to reduce the uncontrolled waste (and its 'derivatives') flows into environment The simple figure of waste flow is as follow:

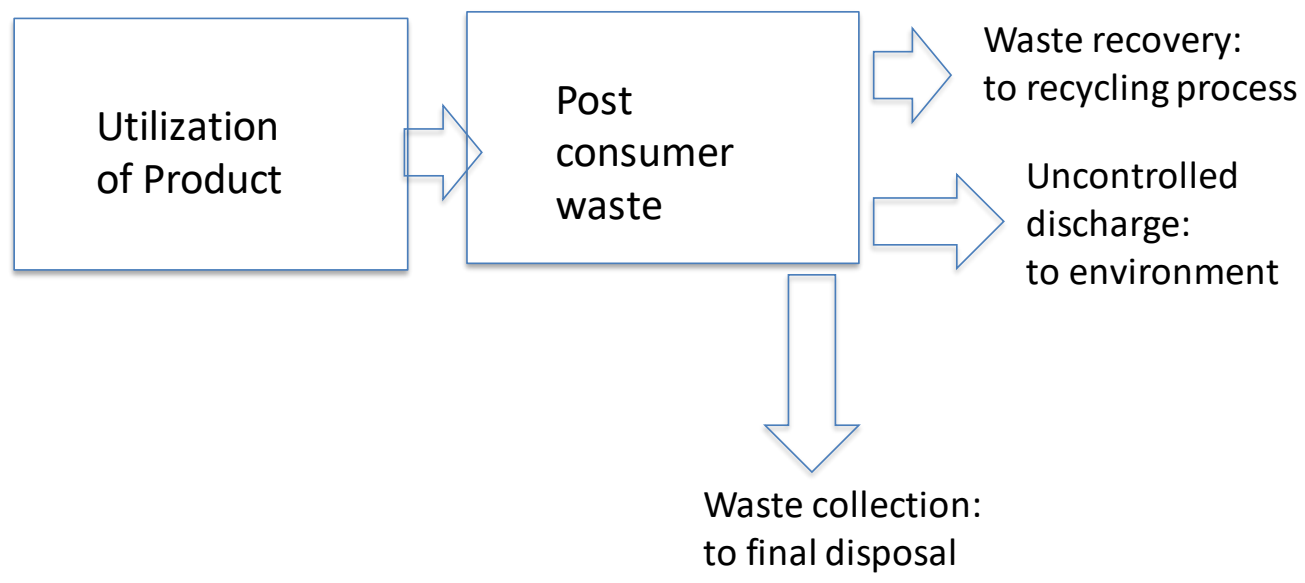

\section{How should we do:}

1. To increase the rate of waste collection services and to improve its quality:

a. Formal waste collection types:

- individual-direct collection $\rightarrow$ the best services (ideal condition)

- individual-undirect-collection $\rightarrow$ require transfer point: vulnerable to the aesthetics if this transfer point is not properly managed

- communal-direct collection $\rightarrow$ the minimum requirement for the best services

- communal-undirect-collection $\rightarrow$ the minimum requirement by formal services, require transfer point: vulnerable to the aesthetics if the transfer point is not properly managed (the worst services) 
b. Common practices:

- Most of the formal waste collection are initiated, managed and operated by the community (role of RTs/RWs) with or without assistance-support (technically-financially) from municipality. In many cases, no integration between community effort and municipality task. This is a 'hidden' participation of community which are rarely appreciated. The quality of the services of waste collection will depend on the ability of the community to organize this 'semi-formal' waste collector. Practically, there is no coordination between waste collection activity and the waste transportation managed by the City Cleanliness division.

- Quality of waste collection by community depends on the ability, capacity and awareness of these RTs/RWs. Some of the standard facility is 'gerobak' (handcart) that was being used in Japan more than 60 years ago. It is less 'humane'. Some cities, like Bandung city, has started to utilize motor-cart (tricycle) for Kelurahan (not for RTs-RWs) to clean and to collect waste from public utilities.

c. Hypothesis:

- If we could increase the rate of community participation, and could 'bridge' the gap between these sectors, the rate of collection would be increased.

- If we want to increase both rate of services and its quality, we start first by communalundirect-collection, toward to the best services: individual-direct-collection.

- If we want to increase efficiency of waste collection and at the same time to improve the quality of the system, we should support a program that are encouraging the utilization motor-cart (tricycle) instead of 'gerobak' in RTs/RWs for collecting waste from households, as one way to improve the quality of services.

- When the rate of collection increases, but not accompanied by the capacity of waste transportation to TPA, it will be a lot of waste 'waiting' in the city to be transported to the TPA. Then the existence of ITF and waste reduction would become an important program.

2. To increase the waste recovery and to improve the quality of recyclable materials:

a. Waste reduction program:

- Waste recovery program (known as 3Rs program) is highly supported by government. The development of bank of garbage and TPS-3R/TPST are the common program that are implemented everywhere in Indonesia. 
- Most of bank of garbage and TPS-3R facilities that have been developed (physically) by local-central government are only functioned and operated in the beginning. The outcome of these programs is not the number of facilities, but whether these facilities function well in accordance with its objective.

b. Hypothesis:

- If we could increase the rate of these activities, it could not always increase the rate of collection rate. We will increase both the collection rate and the recovery rate if we introduce the recycling activity in a community which are not having formal collection services yet. If we introduce it in a community which are having formal collection system, we only increase the rate of recovery.

- If we could increase the rate of participation both community and management of TPS3R Facts, it could increase the waste recovery rate for recycling. The program to support awareness, ability and autonomy of community (or management) of these facilities for sustainability would more important than program to build similar physical facilities.

- If we could increase the number of bank of garbage and TPS-3R (and similar), it could not always increase the rate of recycling. The dominant views in understanding the 3Rs concept are always associated with any effort in urban waste management. Very rarely the waste recovery in MSW management associated with efforts to gain quality of recyclable waste in accordance with the quality required by recycling market.

3. To reduce the uncontrolled waste (and its 'derivatives') flow into environment

a. Littering behavior:

- The practice of waste littering by people in their neighborhood where they live usually occurs because unavailability of waste collection system, or unavailability of public storage (transfer) near their settlement. In general, Indonesian people do not want their house and their neighborhood to be dirty. So they will be looking for a location to dispose off their waste; the principle of not-in-my backyard is applied. For those who have the ability, they will pay people to get rid of their waste.

- Waste scattered is usually found in public places (market, recreation area, etc.). The behavior of trash littering anywhere will be obvious, although at this location the public trash-bin is already available. The problem is, there is no 
consistent law enforcement, although the related regulations is already available.

b. Hypothesis:

- If we could increase the coverage area of collection services at minimum requirement, particularly in areas that are less able to organize the transport of waste through the initiative of RTs/RWs, or by organizing waste recovery program intensively, then the practice of littering will be reduced

- If the city authorities consistently enforce and implement a ban for not waste littering in public palaces, then the behavior of littering will be reduced.

Bandung, 15 February 2017 